\section{Pacific Northwest}

National Laboratory

Operated by Battelle for the

U.S. Department of Energy

\title{
User's Guide for Getter Rate Test System
}

M.R. Elmore

June 2007

Prepared for the U.S. Department of Energy under Contract DE-AC05-76RL01830 


\title{
DISCLAIMER
}

This report was prepared as an account of work sponsored by an agency of the United States Government. Neither the United States Government nor any agency thereof, nor Battelle Memorial Institute, nor any of their employees, makes any warranty, express or implied, or assumes any legal liability or responsibility for the accuracy, completeness, or usefulness of any information, apparatus, product, or process disclosed, or represents that its use would not infringe privately owned rights. Reference herein to any specific commercial product, process, or service by trade name, trademark, manufacturer, or otherwise does not necessarily constitute or imply its endorsement, recommendation, or favoring by the United States Government or any agency thereof, or Battelle Memorial Institute. The views and opinions of authors expressed herein do not necessarily state or reflect those of the United States Government or any agency thereof.

\author{
PACIFIC NORTHWEST NATIONAL LABORATORY \\ operated by \\ BATTELLE \\ for the \\ UNITED STATES DEPARTMENT OF ENERGY \\ under Contract DE-AC05-76RL01830
}

Printed in the United States of America
Available to DOE and DOE contractors from the Office of Scientific and Technical Information,
P.O. Box 62, Oak Ridge, TN 37831-0062;
ph: (865) 576-8401
fax: $(865)$ 576-5728
email: reports@adonis.osti.gov

\begin{abstract}
Available to the public from the National Technical Information Service, U.S. Department of Commerce, 5285 Port Royal Rd., Springfield, VA 22161 ph: (800) 553-6847 fax: $(703) 605-6900$ email: orders@ntis.fedworld.gov online ordering: http://www.ntis.gov/ordering.htm
\end{abstract}

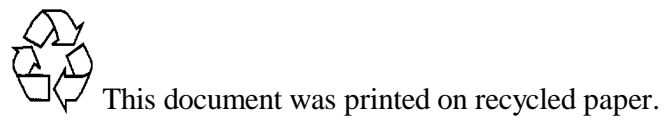


PNNL-16675

\title{
User's Guide for Getter Rate Test System
}

\author{
M.R. Elmore
}

June 2007

Prepared for

the U.S. Department of Energy under Contract DE-AC05-76RL01830

Pacific Northwest National Laboratory

Richland, Washington 99352 



\section{Contents}

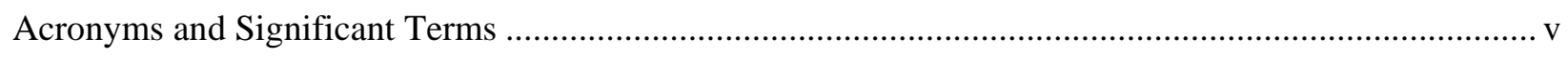

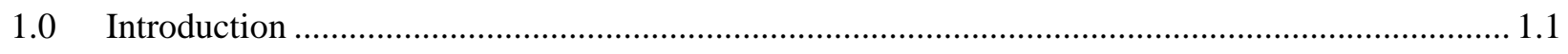

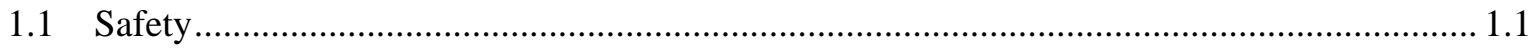

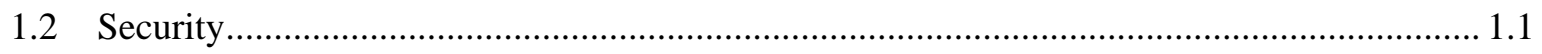

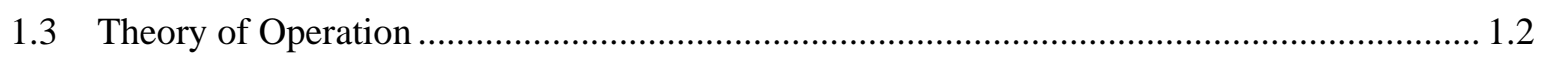

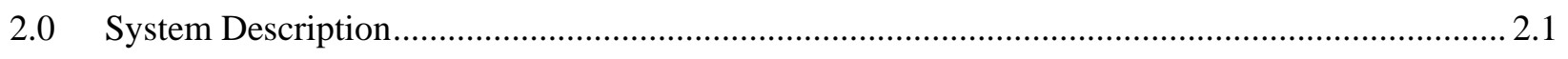

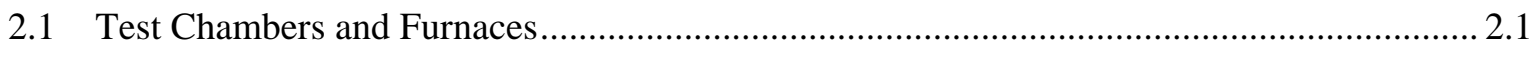

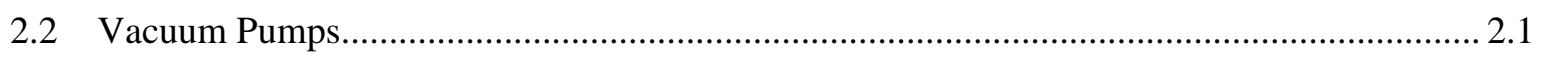

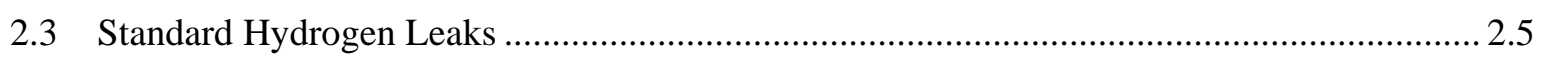

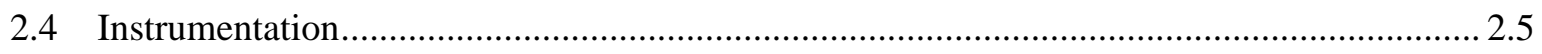

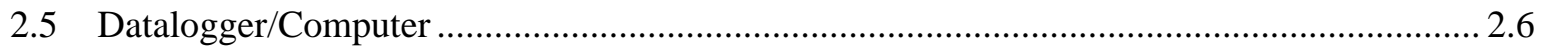

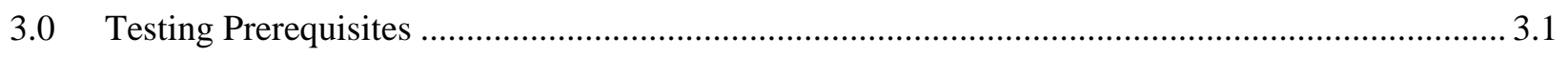

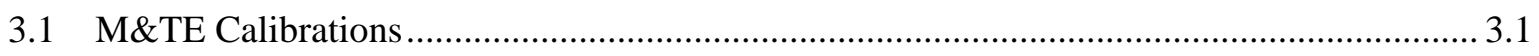

3.2 Calculating Test Chamber Volumes............................................................................ 3.1

3.3 Performance Checking of the Standard Hydrogen Leaks ................................................. 3.2

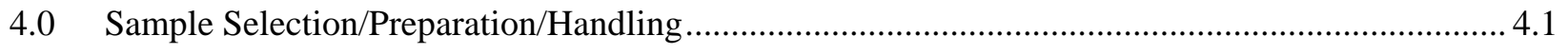

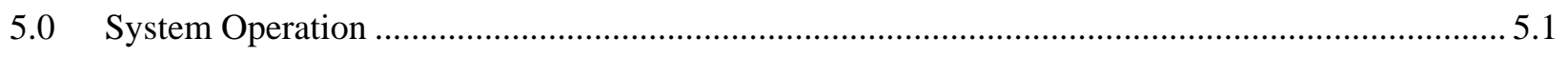

5.1 System Start Up (Vacuum Gauges, Vacuum Pumps, and Furnaces) ................................. 5.1

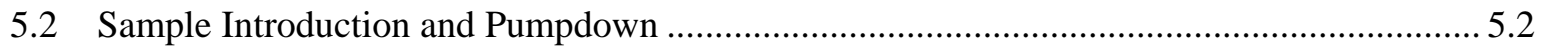

5.3 Datalogger Operation ............................................................................................. 5.3

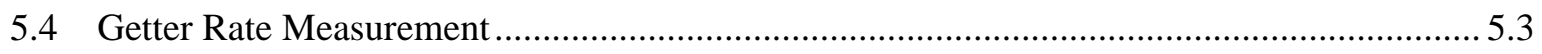

5.4.1 Part 1-Pressure Plateau Method.......................................................................... 5.3

5.4.2 Part 2-Pressure Decay Method …….................................................................. 5.4

5.4.3 Excel Spreadsheet Calculations........................................................................... 5.5

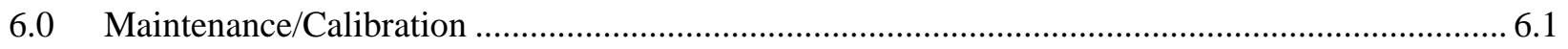




\section{Figures}

1.1. Illustration of System Pressure During the Getter Rate Test...

2.1. Overall View of Getter Rate Test System Showing Furnaces and Test Chambers on Lower Cabinet Section

2.2. Quartz Test Chamber in Lindberg/Blue M Tube Furnace

2.3. Quartz Test Chamber Showing Use of Internal Encapsulated Magnet and External Hand-Held Magnet for Moving Test Sample Into and Out Of the Heated Zone of the Furnace

2.4. Locations of Low-Vacuum Roughing/Fore Pumps, Standard Hydrogen Leaks, and Pressure Transducers in the Main Cabinet.

2.5. Location of Turbo Pump in Main Cabinet.

2.6. Location of Vacuum Control Valve Handles on Outside of Main Cabinet (One Set on Each Side for Each Test Chamber).

5.1. Possible Outcomes for Pressure Decay Test...... 5.4

5.2. Example Spreadsheet Calculation for Getter Rate Coefficient. 


\section{Acronyms and Significant Terms}

A/D

CNR

CRD

Getter

Getter Rate

Getter Rate Coefficient

M\&TE

Protium

Standard Hydrogen Leak

TPBAR

UHP

VTI
Analog-to-digital

Commercial Nuclear Related

Confidential/Restricted Data

Nickel-plated and heat-treated zirconium components of TPBARs that absorb hydrogen isotopes in the TPBARs during in-reactor exposure.

The rate that a getter absorbs hydrogen from a gas phase

Rate "constant" derived from the getter rate expression. The getter rate coefficient is the target performance value given in the design specification, and the value that is determined and reported from the getter rate test.

Measuring and test equipment

The common and most abundant of the three hydrogen isotopes (protium, deuterium, and tritium). Protium is typically called hydrogen, for example, when describing the standard "hydrogen" leaks used in the getter rate test.

Pressurized cylinders of hydrogen gas that supply a constant flow rate of hydrogen to the getter rate test through a calibrated capillary orifice.

Tritium Producing Burnable Absorber Rod

Ultra high purity

Vacuum Technologies, Inc. 



\subsection{Introduction}

This User's Guide describes the operation and maintenance of the Getter Rate Test System, including the mechanical equipment, instrumentation, and datalogger/computer components. The Getter Rate Test System includes equipment and instrumentation to conduct two getter rate tests simultaneously. The mechanical equipment comprises roughing and high-vacuum pumps, heated test chambers, standard hydrogen leaks, and associated piping and valves. Instrumentation includes thermocouples, pressure (vacuum) transducers, panel displays, analog-to-digital signal converter, and associated wiring. The datalogger/computer is a stand-alone computer with installed software to allow the user to record data input from the pressure transducers to data files and to calculate the getter rate from the data in an Excel ${ }^{\circledR}$ spreadsheet.

\subsection{Safety}

The Getter Rate Test System has the following potential hazards and should be operated accordingly:

Pressure - The test system uses high-pressure ( 1000 psi) hydrogen cylinders for the standard leaks. Although the leak rates are extremely low, pressure can build up between the orifices and the shut-off valves on the cylinders. The sudden opening of a valve to a closed test system could pressurize the system, potentially resulting in damage to the pressure transducer and/or quartz tube. To avoid this, open the valve on the standard leak slowly to a vented system or while the test system is being evacuated by the roughing pump.

Vacuum - The test system typically operates at moderate vacuum (down to $\sim 10^{-4}$ torr). This represents a moderate level of stored energy in the system. Caution should be used around the quartz furnace tubes to avoid breaking them, which could result in flying quartz shards.

High Temperatures-Furnace temperatures may run up to $\sim 500^{\circ} \mathrm{C}$ or higher, depending on the nature of the test. The furnaces are well insulated to prevent exposure to high temperatures. Caution should be used to avoid burns from the quartz furnace tubes that extend out of the ends of the furnaces.

Electrical-The system operates on 110 VAC. The risk of electrical shock is low. However, exposed electrical contacts are present inside the instrument cabinet. Caution should be used to avoid coming in contact with exposed electrical connections when working in the instrument cabinet.

Fragile Quartz Tubes-The quartz furnace tubes are fragile. Caution should be exercised when handling the tubes to avoid cuts from a broken tube.

\subsection{Security}

The test samples, data files, and calculations will typically be classified confidential restricted data (CRD) and should be handled accordingly. The computer collecting and analyzing the data from the Getter Rate Test System is a classified information system and must be handled accordingly. Displays of the test temperature and instantaneous pressure readings on the instrument panel are not classified and do not need to be protected. 


\subsection{Theory of Operation}

The capability of nickel-plated zirconium components to selectively absorb (getter) isotopes of hydrogen is a critical performance characteristic of the tritium producing burnable absorber rods (TPBARs). The lower the tritium partial pressure in a TPBAR during in-reactor operation, the less tritium will permeate into the reactor coolant. In-reactor measurement of this absorption rate (gettering rate) has been estimated during "post irradiation examination" of a limited number of TPBARs, but is impractical on a routine basis. Additionally, the ability to measure the gettering rate before TPBAR components are fabricated helps to verify that substandard components do not go into a reactor.

The Getter Rate Test System and test method are designed to evaluate the capability of a getter sample to absorb "protium" hydrogen and thereby predict the relative in-reactor performance of nickelplated zirconium getter components. The test system and method are designed to test small samples of getter tubing ( 1 in. to $2 \mathrm{in}$. long) and individual or multiple getter disks. (Longer tube samples may have a non-uniform temperature distribution over their length in the small tube furnaces included in the test system.)

The absorption of hydrogen by the getter is both temperature dependent and pressure dependent. The test temperature is established by Test Plan, Work Instruction, etc., and is held constant over the length of the test. The getter rate test is a two-part test; either or both parts may be performed (typically both parts of the test are performed for each getter rate test). Part one of the test begins with an evacuated test chamber and uses the standard hydrogen leak to provide hydrogen gas into the system. Because the getter rate is pressure dependent, the system pressure (hydrogen gas) will typically increase to some value and then plateau as the system reaches equilibrium where the rate that the sample is absorbing hydrogen is equal to the rate that hydrogen is flowing into the system from the standard leak. This is illustrated in Figure 1.1. A getter rate coefficient can be determined from the leak rate, sample surface area, etc. This calculation is described in later sections.

The second part of the test involves shutting off the standard leak and monitoring the system pressure as the remaining hydrogen is absorbed by the getter. During this phase, the pressure decays to near zero (there will be some pressure of hydrogen in equilibrium with the getter, but this will probably be too low to measure). Exceptions to this behavior may be due to:

- A vacuum leak in the system so air is leaking into the test chamber,

- The test sample is off-gassing,

- Surface oxide on the sample is reacting with hydrogen to form water vapor that is not then absorbed by the getter.

For these exceptions, the system pressure would tend to increase and not reach an equilibrium plateau in Part 1 (in the case of an air leak), or in Part 2, the final pressure would be significantly higher than zero (when a non-hydrogen gas species is present). 


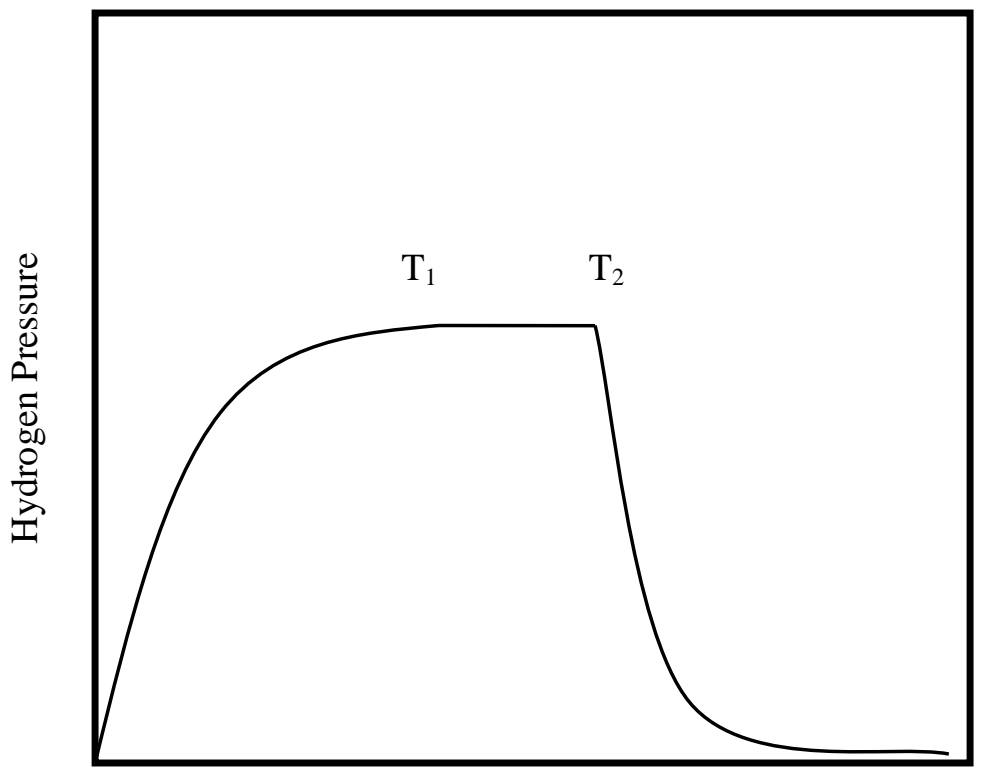

Time

Figure 1.1. Illustration of System Pressure During the Getter Rate Test. In Part 1, pressure increases up to time (T1) and is then constant as the rate of hydrogen absorption by the getter is equal to the rate hydrogen enters from the standard leak. In Part 2, beginning at T2, the standard leak is shut off, and the remaining hydrogen in the system is absorbed by the getter to some lower equilibrium pressure.

An alternate getter rate coefficient can be determined from the pressure decay portion of the curve in Figure 1.1, just to the right of $\mathrm{T}_{2}$. The rate coefficient from Part 1 is usually the reported value. However, agreement between the two values is an indication of an acceptable test.

Once the test is complete, the sample can be removed from the test chamber, the system can be vented to the atmosphere, and another sample can be loaded into the chamber for testing. Details of this test procedure and data analysis are presented in the following Sections. 



\subsection{System Description}

The Getter Rate Test System is mounted in and on a two-part cabinet and comprises the following subsystems:

- Test chambers and furnaces,

- Vacuum pumps and associated piping and valves,

- Standard hydrogen leaks and associated piping and valves,

- Instrumentation, including pressure sensors and thermocouples, displays, an analog-to-digital (A/D) signal converter, and associated wiring,

- Datalogger/computer system for data collection and analysis.

Figure 2.1 shows the overall test system and cabinet (not including the computer). The furnaces and test chambers are located on the front, lower section of the cabinet. The instrument displays, pump controls, and power switches are located on the front of the taller section of the cabinet. The taller main cabinet encloses the vacuum pumps, standard hydrogen leaks, pressure (vacuum) instrumentation, A/D converter, and most of the piping and wiring. Extra storage is provided under the furnaces in the lower section of the cabinet.

The only service required for operating the Getter Rate Test System is 110-VAC electricity. This runs the pumps, furnaces, and instrumentation. The main power cords are located in the bottom of the main cabinet.

\subsection{Test Chambers and Furnaces}

Figure 2.2 shows one of the test chambers and the electrical tube furnace used to heat the test chamber. The test chamber is $1 / 2$-in. diameter quartz tubing with fire-polished ends. The test chamber is sealed to the system with Ultratorr ${ }^{\circledR}$ (O-ring) fittings at each end.

Two quartz-encapsulated magnets are located in each test chamber (one in each end) to move the test sample into and out of the heated zone of the furnace, using a hand-held magnet as shown in Figure 2.3. This allows the furnace to remain heated to the test temperature throughout the operation, and the sample can be moved into the heated zone once the system has been evacuated by the vacuum pumps.

The furnaces are Lindberg/Blue M (1 in. $\times 12$ in.) tube furnaces rated to $1100^{\circ} \mathrm{C}$. The furnace on/off switch and setpoint controls are located on the lower front panel of each furnace. Specifications for the furnaces include $120 \mathrm{VAC}, 6.8 \mathrm{amps}, 0.8 \mathrm{~kW}$, and 50/60 Hz. Power is supplied through outlets inside the main cabinet.

\subsection{Vacuum Pumps}

The two-stage vacuum pumping system includes two oil-filled roughing pumps (Edwards Model E2M1.5) and a high-vacuum turbo-molecular pump (Edwards Model EXT70). (One of the first-stage pumps acts as a roughing pump and the other as a fore pump to protect the turbo pump.) Canisters containing molecular sieve alumina beads are located on the vacuum side of both oil pumps to prevent oil 
vapor from back-streaming into the rest of the vacuum system. A system of valves and piping crossovers allows each test chamber to be evacuated independently using the one set of pumps. The pumps run continuously during operation. The vacuum pumps, valves, and piping are shown in Figures 2.4 and 2.5. The start/stop switch and speed indicator for the turbo pump are located on the EXC120 panel on the front of the main cabinet (see Figure 2.2).

Control valves to evacuate the test chambers are operated from handles on the outside of the main cabinet (one set on each side for each test chamber). See Figure 2.6.

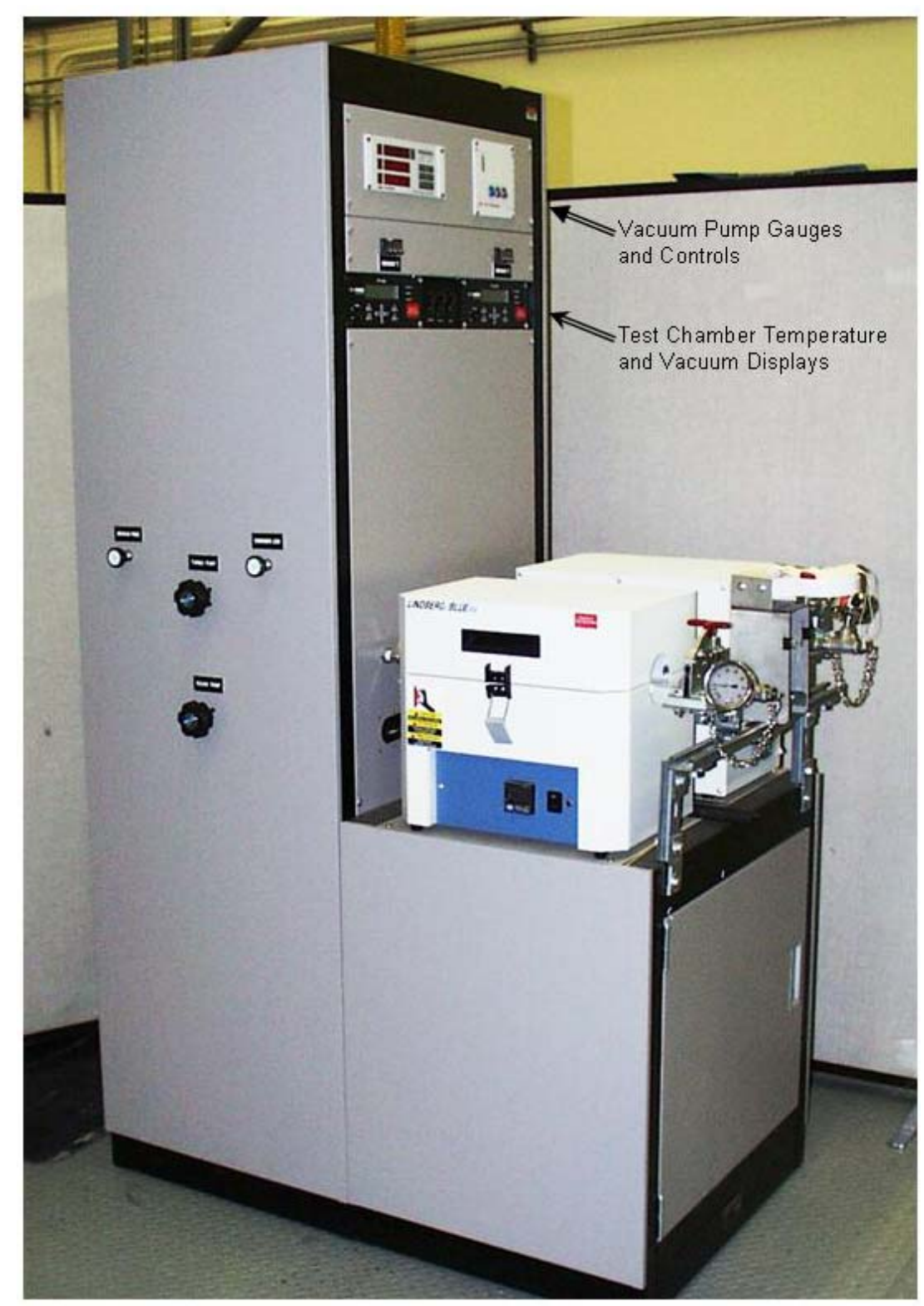

Figure 2.1. Overall View of Getter Rate Test System Showing Furnaces and Test Chambers on Lower Cabinet Section. (Note: instrumentation displays and control valves on front and sides of main cabinet section. Pumps, hydrogen leaks, piping, etc. are accessed from the rear of the main cabinet.) 


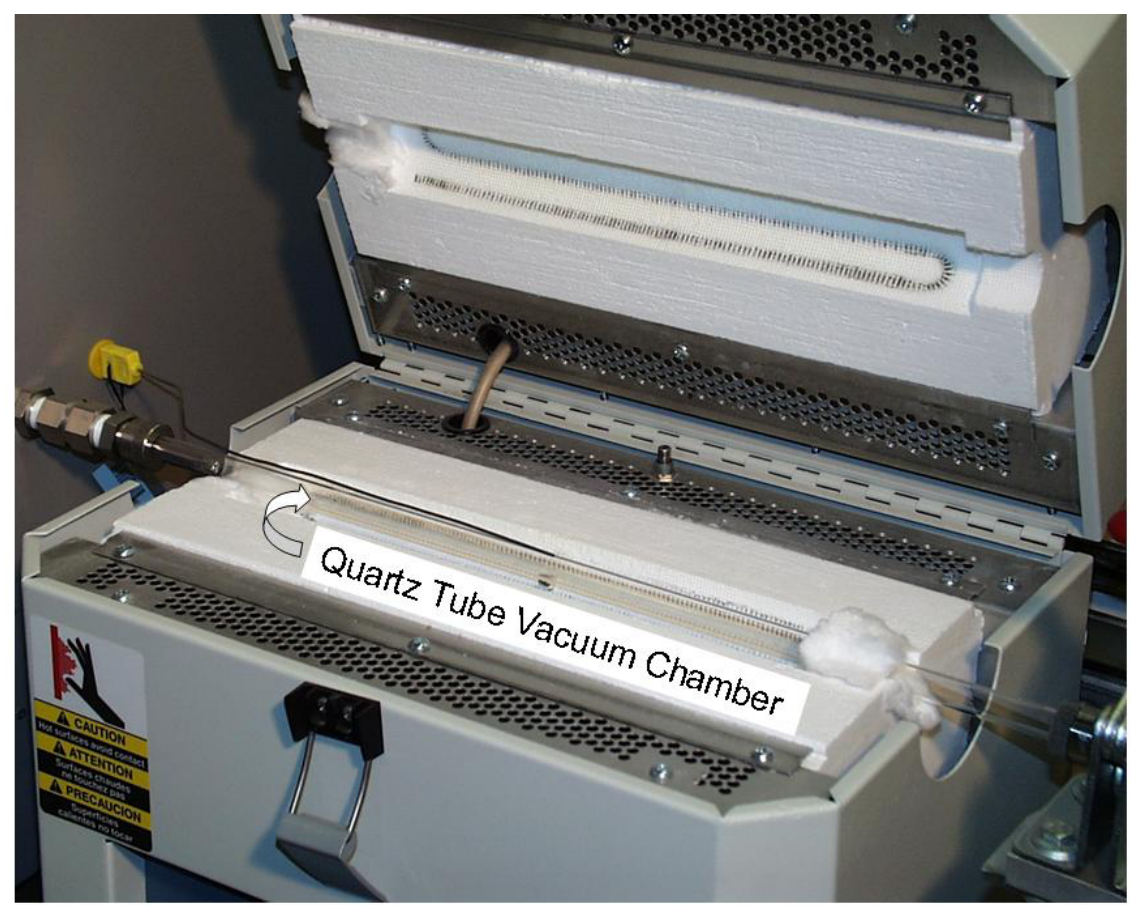

Figure 2.2. Quartz Test Chamber in Lindberg/Blue M Tube Furnace. This shows one of two identical test chambers/furnaces located on top of the lower cabinet. (Note: the thermocouple attached to the quartz tube near the midpoint of each furnace to measure test temperature.)

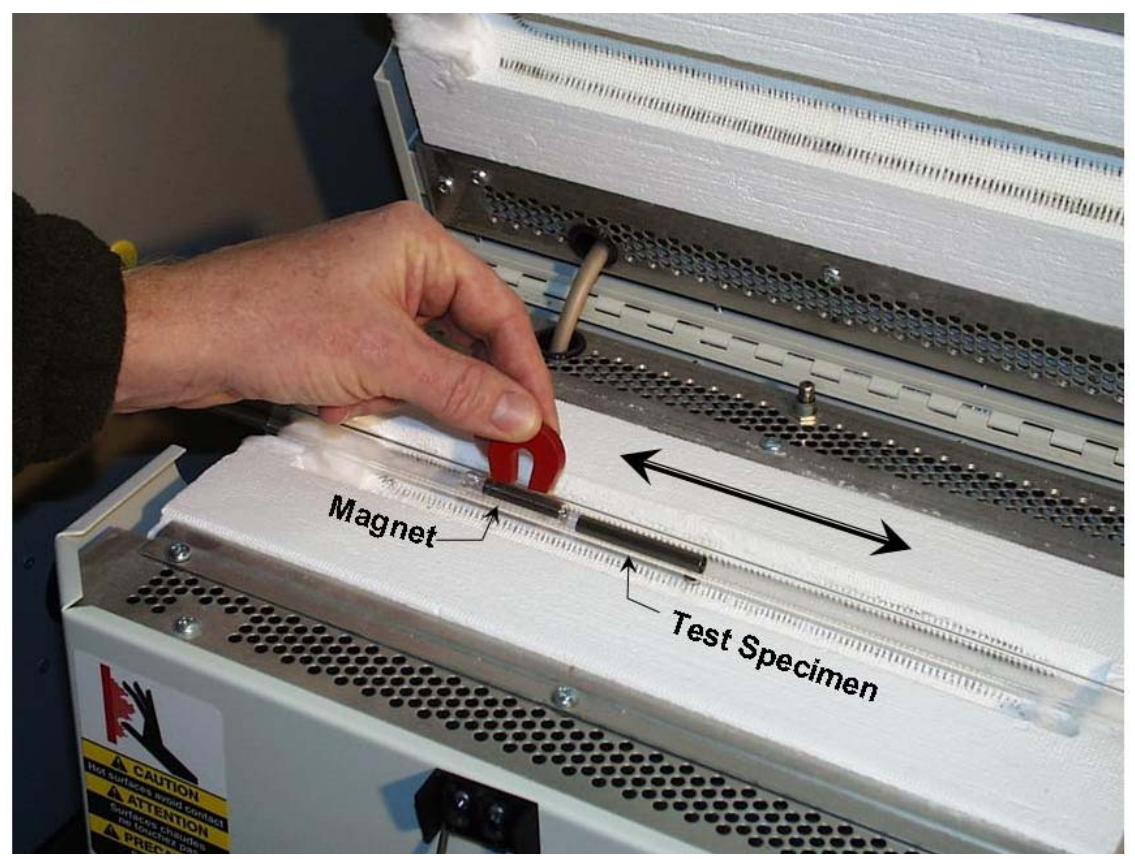

Figure 2.3. Quartz Test Chamber Showing Use of Internal Encapsulated Magnet and External HandHeld Magnet for Moving Test Sample Into and Out Of the Heated Zone of the Furnace 


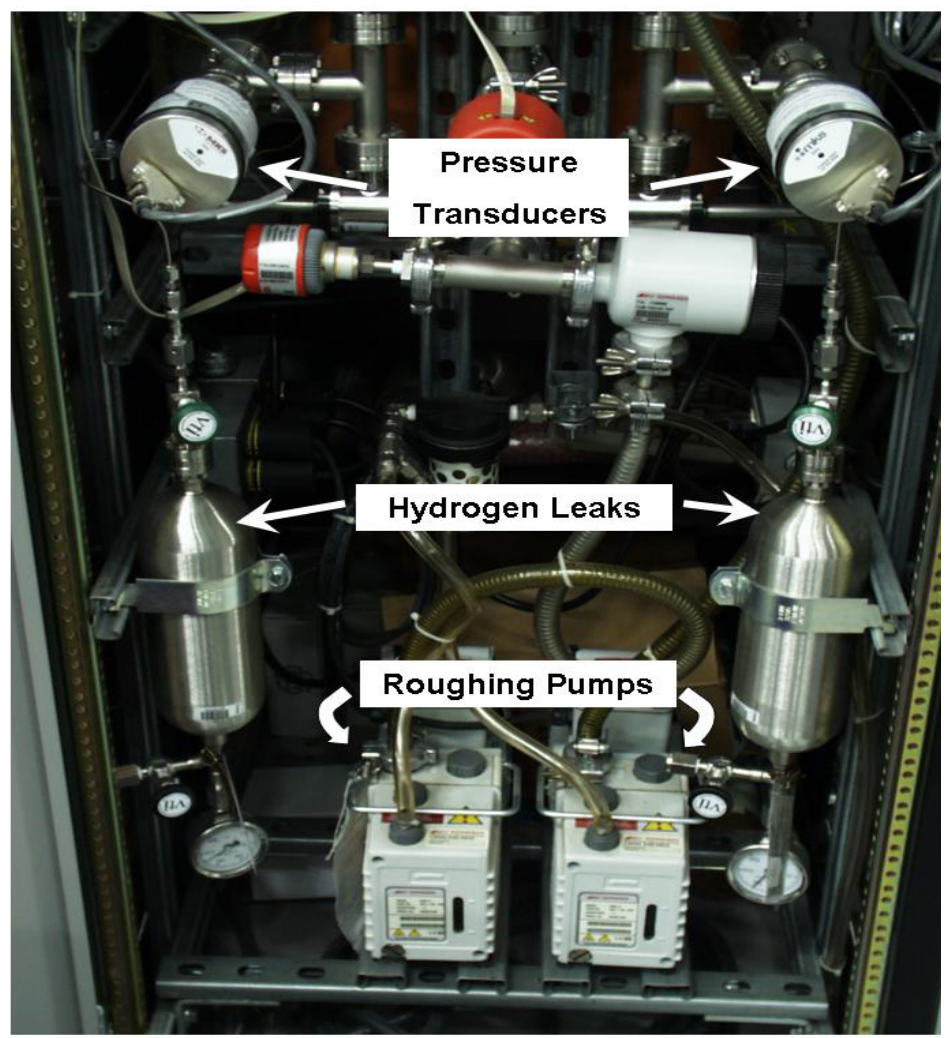

Figure 2.4. Locations of Low-Vacuum Roughing/Fore Pumps, Standard Hydrogen Leaks, and Pressure Transducers in the Main Cabinet

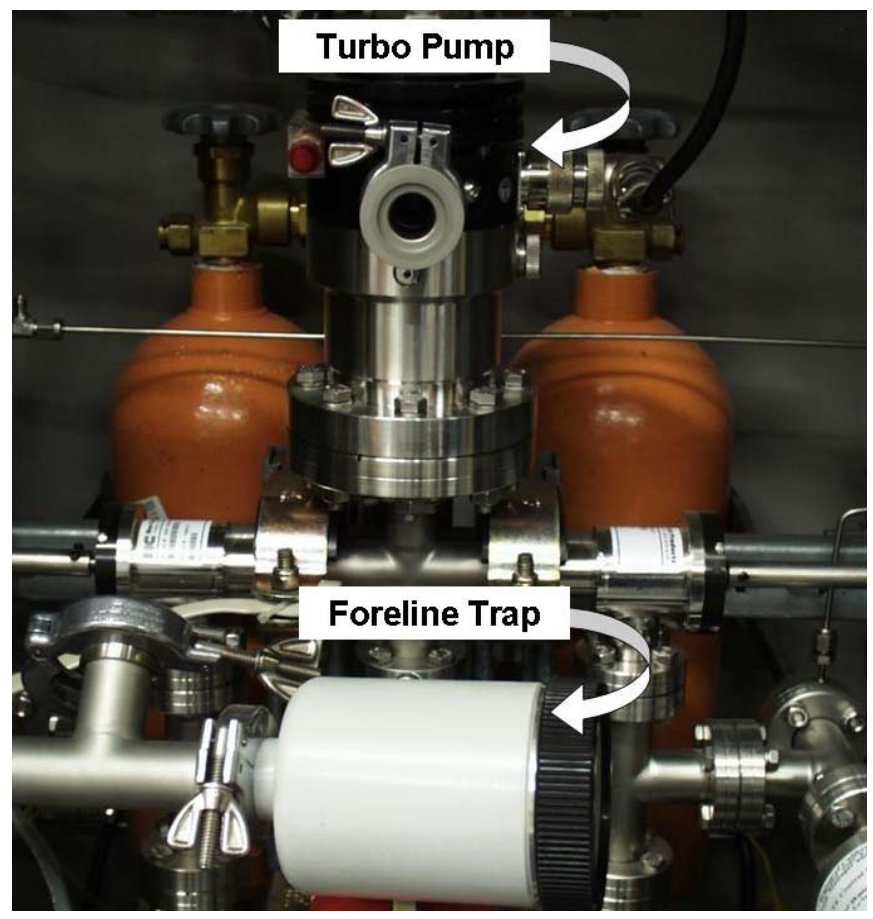

Figure 2.5. Location of Turbo Pump in Main Cabinet. This view shows the thermocouple gauge and foreline vapor trap removed for clarity. 


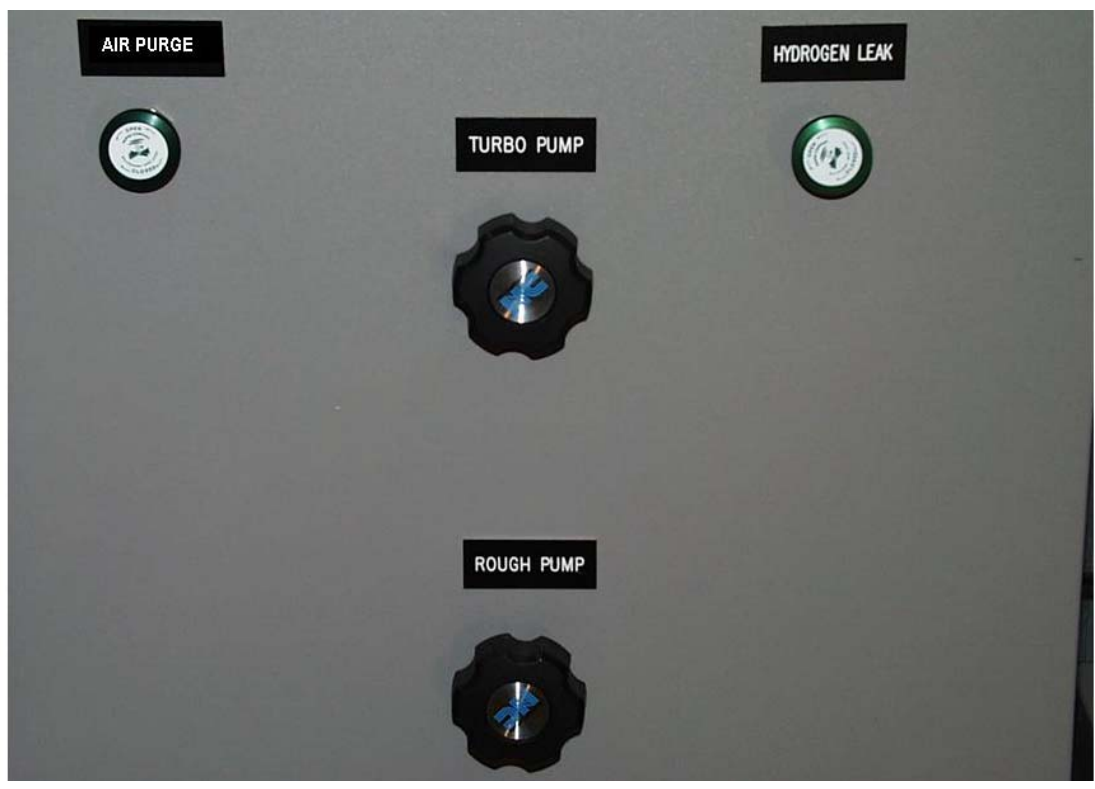

Figure 2.6. Location of Vacuum Control Valve Handles on Outside of Main Cabinet (One Set on Each Side for Each Test Chamber).

\subsection{Standard Hydrogen Leaks}

The standard hydrogen leak is a high-pressure ( 1000 to 1500 psi) cylinder attached to a calibrated capillary leak that permits a low and constant flow of gas (hydrogen) to flow from the reservoir into the test system through a shutoff valve. A fill valve is located at the other end of the cylinder. The standard leaks are filled with ultra high purity (UHP) hydrogen and calibrated by Vacuum Technologies, Inc.

(VTI) in Oakridge, TN, and are available in a variety of flow rates (typically $10^{-5}$ to $10^{-3} \mathrm{~atm} \mathrm{cc} / \mathrm{sec}$ for this testing). Figure 2.4 shows the standard leaks (one for each test chamber) installed in the main cabinet. For operator convenience, an alternate shut-off valve for each standard leak is located on the outside of the main cabinet near the vacuum control valves (see Figure 2.6).

\subsection{Instrumentation}

The principle test parameters monitored by instrumentation includes temperature and pressure. The test temperature is measured by calibrated Type $\mathrm{K}$ thermocouples (one for each test chamber) attached to the quartz tubes near the midpoint of each furnace (see Figure 2.2). The temperature of each chamber is displayed on the front panel of the main cabinet.

The test chamber pressure (vacuum) is measured by MKS Baratron pressure transducers located inside the main cabinet (see Figure 2.4). Analog signals from the transducers are sent to an analog-todigital converter (IOTech Personal DAQ/56). This converts the analog inputs to digital signals that are then sent to the datalogger/computer to collect and analyze data.

Other pressure-measurement instruments are included to monitor the operation of the pumps, but are not used to collect test data. The additional pressure measurements include two Edwards Active Thermocouple gauges (65 to $10^{-3} \mathrm{mbar}$ ) for the inlets to the two roughing pumps and one Edwards Active 
Inverted Magnetron gauge ( $10^{-2}$ to $\left.10^{-9} \mathrm{mbar}\right)$. Readings for these gauges are displayed on the Edwards Active Gauge Controller panel on the front of the main cabinet (see Figure 2.1).

\subsection{Datalogger/Computer}

The datalogger/computer is a standard PC running Windows with IOTech software for data acquisition and Microsoft Excel for analysis. To collect data from a getter rate test, the PC is booted, and the IOTech software is started in the logging mode. The test is conducted, and on completion, the datalogging file is saved. Displays of the data during the test are user selectable from pull-down menus. A complete description of the data-logging software can be found in the IOTech software User's Manual. The data are analyzed by importing the pressure vs. time data into an Excel spreadsheet and calculating, for example, a getter rate coefficient from the data and appropriate rate equation. The details of the analysis with the Excel spreadsheet are described in a later section. 


\subsection{Testing Prerequisites}

This section describes prerequisites that must be performed before beginning commercial nuclear related (CNR) getter rate tests and then periodically as required by procedure, Quality Assurance Plan, etc.

\subsection{M\&TE Calibrations}

The measuring and test equipment (M\&TE) instrumentation used for getter rate testing must be calibrated according to the applicable Quality Assurance Plan requirements. The following M\&TE items are used for this testing. Before using the M\&TE, verify that the current date is within the calibration interval shown on the calibration stickers on the instruments.

Calipers - Calipers are used to measure the length and diameter of the test samples, which are then used to determine the surface area in the "getter rate calculation spreadsheet." The selected calipers should give dimensions to the nearest $0.5 \mathrm{mil}$ (0.0005 in.). The typical calibration interval for the calipers is 1 year.

Thermocouples-Type K thermocouples monitor temperatures of the test chambers. They are "calibrated" to typical manufacturing specifications over a range that will include the standard test temperatures (e.g., ambient to $500^{\circ} \mathrm{C}$, at least three points). Accuracy should be at least $\pm 5^{\circ} \mathrm{C}$. The typical calibration interval for the thermocouples is 2 years.

Pressure Transducers-The MKS Baratron pressure transducers monitor the hydrogen pressure in the test system throughout the test. They are calibrated to manufacturing specifications over the full range of the instruments (e.g., 0 to 10 torr in 1-torr increments). Accuracy for the Baratron pressure transducer is typically $\pm 1.5 \%$ of full-scale reading. The typical calibration interval for the pressure transducers is 1 year.

Hydrogen Leak Sources-The hydrogen leak sources provide a suitably constant flow of hydrogen to the test sample during the first phase of the getter rate test. The typical calibration interval for the standard hydrogen leaks is 1 year. Performance tests of the hydrogen leaks are conducted at shorter intervals determined by the level of use or suspected problems to detect degraded performance of the leaks. This performance check is described below.

\subsection{Calculating Test Chamber Volumes}

An accurate measure of the volume of each test chamber is required to calculate the getter rate from the pressure data. Before performing a getter rate test, the evacuated volume of each test chamber must be determined. If any subsequent changes are made to the test system that would affect the volume calculations (e.g., replacing a broken quartz test chamber) the volumes must be redetermined.

1. To determine the test chamber volume, start with the test system at ambient temperature and with a calibrated hydrogen leak and calibrated pressure transducer installed in the system.

2. Seal the system with the encapsulated magnets placed in the chamber.

3. Pump the chamber down with the roughing pump. 
4. Slowly open the shut-off valve to the hydrogen leak to purge high-pressure hydrogen contained between the valve and the leak orifice.

5. Leaving the hydrogen leak valve open, shut the valve to the roughing pump and open the valve to the turbo pump. The system pressure should be essentially zero.

6. Start the data-logging software to collect pressure-time data.

7. Close the valve to the turbo pump and note the time.

8. Allow the hydrogen leak to build up pressure in the system to a pressure of $\sim 2$ to 5 torr for a system equipped with a 10-torr pressure transducer. Note the time at the selected pressure endpoint.

9. Calculate the System Volume according to the following example (Note-this example used a low flow rate leak of $\left.1.5 \times 10^{-5} \mathrm{~atm} \mathrm{cc} / \mathrm{s}\right)$ :

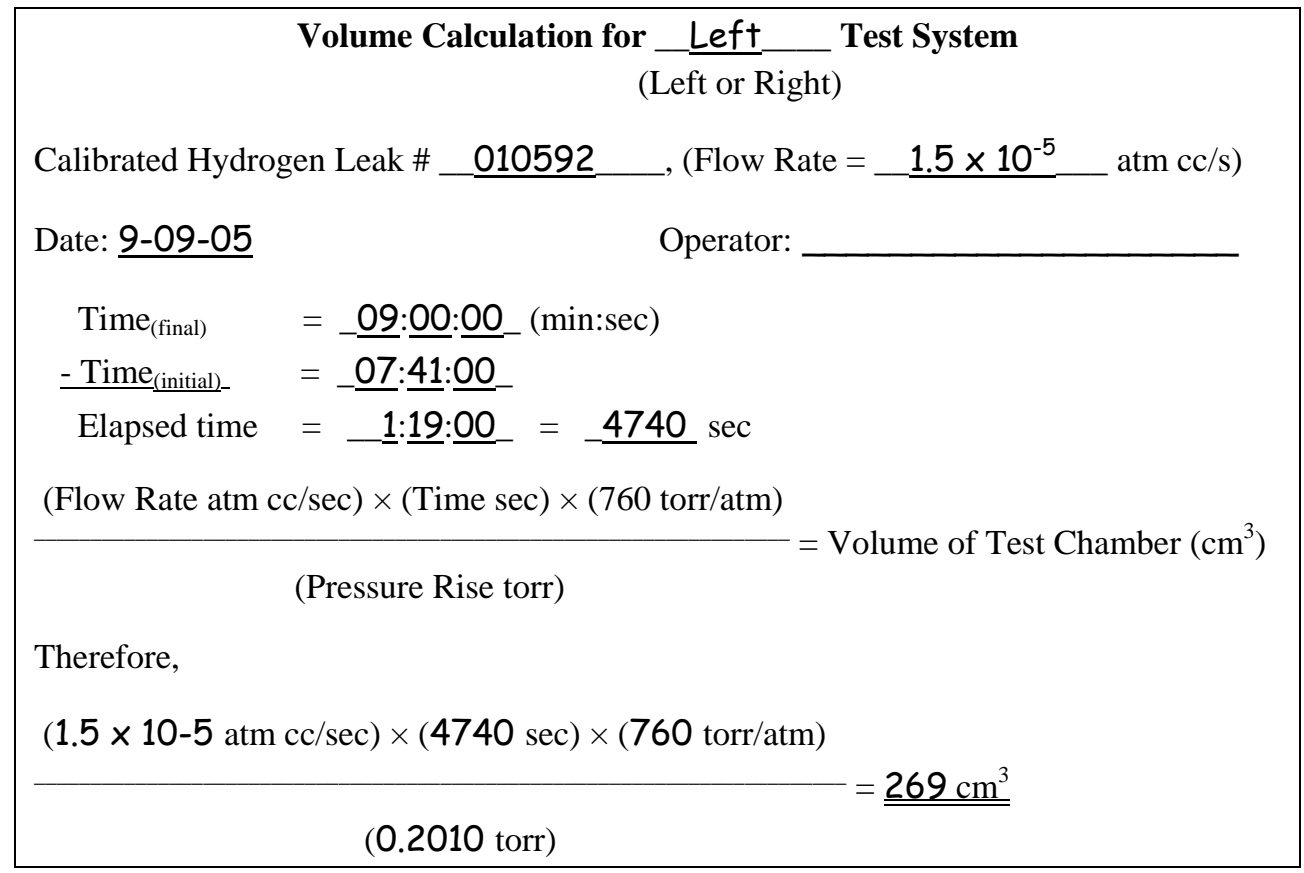

\subsection{Performance Checking of the Standard Hydrogen Leaks}

The flow rate of hydrogen from the standard leaks is assumed to be accurate upon receipt from the calibrating facility. Once every 1 to 2 months during use, or whenever a change in hydrogen flow rate is suspected (e.g., a consistent difference or bias in getter rates determined by the two systems for similar getter samples), the flow rates of the standard hydrogen leaks should be rechecked. This check should also be performed at ambient temperature and is similar to the "volume calculation" shown above, but uses the determined system volume to determine the flow rate from the standard leak.

To check the flow rate of the standard hydrogen leak, begin with the standard leak and a calibrated pressure transducer installed in the system.

1. Seal the system with the encapsulated magnets placed in the chamber.

2. Pump the chamber down with the roughing pump. 
3. Slowly open the shut-off valve to the hydrogen leak to purge high-pressure hydrogen contained between the valve and the leak orifice.

4. Leaving the hydrogen leak valve open, shut the valve to the roughing pump and open the valve to the turbo pump. The system pressure should be essentially zero.

5. Start the data-logging software to collect pressure-time data.

6. Close the valve to the turbo pump and note the time.

7. Allow the hydrogen leak to build up pressure in the system to a pressure of $\sim 2$ to 5 torr for a system equipped with a 10-torr pressure transducer. Note the time at the selected pressure endpoint.

8. Calculate the leak rate for the Standard Hydrogen Leak according to the following example:

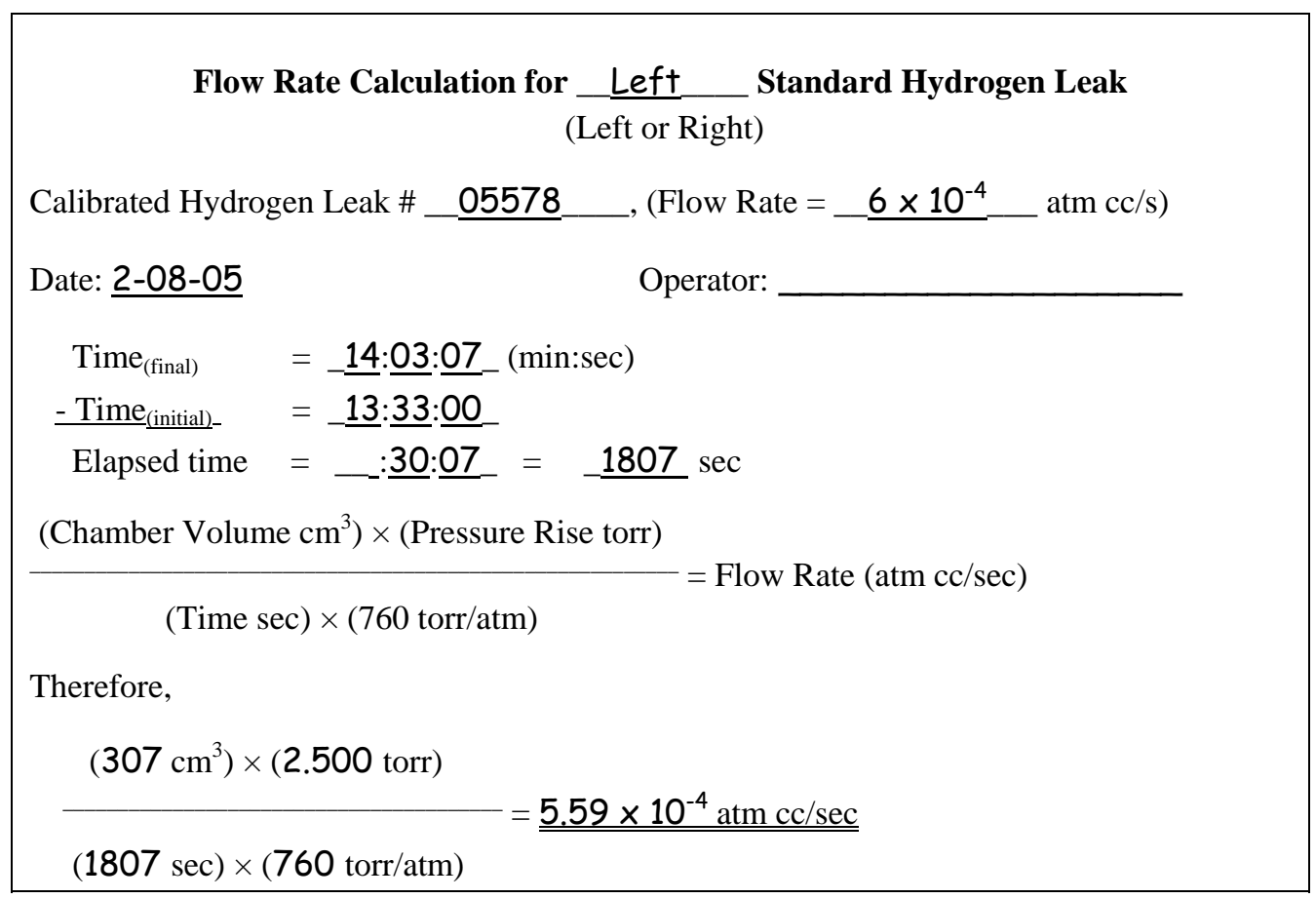





\subsection{Sample Selection/Preparation/Handling}

The Getter Rate Test System has been used extensively to test sections of getter tubes and spacer tubes. The system has also been used less frequently to evaluate getter disks. The flow rates of the hydrogen leak standards, the sizes of the furnaces and test chambers, and the ranges of the pressure (vacuum) transducers have been selected to work well with tube samples approximately 2 inches long ( $\sim 4$ in. $^{2}$ surface area) that exhibit a nominal getter rate (i.e., the time to conduct a test is reasonable). For samples of markedly different sizes, other leak standards, pressure transducers, and/or quartz sample chambers may be necessary for optimum performance.

Getter rate measurements are typically performed on plated, activated getters. For getter-tube and spacer-tube samples, the samples are cut from longer tubes. The cut ends are typically deburred; the samples are cleaned with deionized water, wiped with lint-free cloths, and dried before testing. Note: Significant damage to the plating at the cut ends may be cause to reject the sample for testing. Getter disks that have been heat treated do not need to be cleaned before testing. Test samples have typically been stored in individually labeled Ziploc bags before testing (rather than marking the samples) to avoid contaminating the plated surface.

Cleaned test samples should be handled with tongs, clean lint-free gloves, or an equivalent to prevent contamination of the plated surface. Samples before testing may have a noticeable amount of oxidation of the surface. During the test, some of this oxide can be reduced by the hydrogen gas, forming water vapor. This can lead to a significant residual pressure in the test system at the end of a test. (Noting the surface appearance of the sample before and after the test may help to explain the residual pressure. Photographs of the sample before and after testing may be helpful in explaining anomalous getter behavior.) Correction of the getter rate calculation for this residual pressure is described under Part 2Pressure Decay Method and under Excel Spreadsheet Calculations.

Before getter rate testing is performed, the length and diameter of the test sample are measured with calibrated calipers. The sample ID, length, and diameter should be recorded on a data sheet, log book, etc. for later reference while calculating the getter rate coefficient. The sample is then ready to be loaded into the test chamber. 



\subsection{System Operation}

The "Getter Rate Test System" includes two identical test chambers with duplicate independent vacuum control valves, furnaces, hydrogen leaks, etc. In the following description where a single system is described, it is meant to be applicable to both test chambers.

\subsection{System Start Up (Vacuum Gauges, Vacuum Pumps, and Furnaces)}

Perform the following steps to warm up the vacuum transducers, and start the pumps and furnaces before getter rate testing or standard leak-performance checking.

1. If power to the vacuum gauge transducers has been off, first turn on the "Instruments" switch on the front panel and the power switches to the vacuum gauges on the front of the vacuum-gauge readouts. The transducers are temperature-compensated (electrically heated) to minimize the effects of changing ambient temperatures. The transducers are heated with a small electrical current and can take up to 4 hours for the temperature and vacuum reading to stabilize.

2. At this point, check to see that the individual power switches on the furnaces are off. Next turn on the "Furnaces" switch on the front panel to feed power to the two test-chamber furnaces.

3. Verify that the air-purge valves, the rough-pump valves, and the turbo-pump valves are closed and that the outer test chamber "Ultratorr" fittings are in place and secured.

4. Turn on the roughing pumps using the "Pumps" switch on the front panel. There should be an indication of vacuum from the thermocouple gauge readouts on the Edwards Active Gauge Controller panel on the upper left front panel of the main cabinet.

5. Once the roughing pumps have stabilized, start the turbo pump with the blue "start" switch on the Edwards EXC120 turbo pump controller. A light display on the left side of the controller indicates pump RPM. The turbo pump is capable of high vacuum when the pump speed has reached its maximum value.

6. Slowly open the roughing-pump valves. One should hear the roughing pumps evacuating the test chambers. There should also be indications on the MKS PR4000 readouts on the front panel. If the vacuum transducers have warmed up, the readings should be stable at $\sim 0.02$ to 0.03 torr.

7. Close the roughing-pump valves and note the vacuum readings on the MKS readouts. The reading should be steady or increasing only slightly. A rapid increase indicates an unacceptable air leak, and one should check the Ultratorr fittings, valves, etc. for the leak. If no leak is observed, or only a slight leak (apparent slow leaks can be the result of "virtual leaks" where gases can be trapped in crevices around fittings, etc. and slowly released), slowly open the turbo-pump valves.

8. With the test systems evacuated with the turbo pump, the vacuum readings on the MKS readouts should be zero. If the reading is not zero, an adjustment can be made on the transducer head with a small flat-bladed screw driver (zero adjust).

9. Next perform a leak check on the system. Close the turbo-pump valve, isolating the test chambers from the pumps. Time the leak test for 10 minutes. If the pressure rises no more than $1 \times 10^{-3}$ torr/min, the system can be considered leak tight for the getter rate test. (If the pressure rises faster than $1 \times 10^{-3}$ torr/min, look for the source of the leak. Retighten fittings, check valves, etc. The 
Ultratorr fittings may need a very small film of vacuum grease applied to the O-ring.) If the system is leak-tight, the vacuum system is ready for a getter rate test.

10. Testing Prerequisites:

a. If this is the first time the system has been operated, or if a change has been made to the test system affecting the evacuated volume, perform a system volume calculation as described in the preceding section "Testing Prerequisites" with newly calibrated standard hydrogen leaks.

b. If the system volume has been determined for this configuration, and the standard hydrogen leaks are not newly calibrated, conduct a performance check of the leaks as described in the preceding section "Testing Prerequisites."

11. Turn on the furnace controllers and set the temperature to approximately the test temperature. (The furnace controller setpoint is close to but not the actual temperature of the chamber.) The actual temperature is measured by the calibrated thermocouple in contact with the quartz tube near the middle of the heated zone. Adjust the furnace temperature controller until the desired test temperature, which is displayed on the thermocouple readout on the front panel, is steady.

\subsection{Sample Introduction and Pumpdown}

With the roughing pumps and the turbo pump running, valves closed, system purged to atmospheric pressure, and furnace steady at the test temperature, the prepared test sample is inserted into the outer end (unheated section) of the test chamber, and the system is evacuated and checked for leak tightness according to the following steps.

1. Check to verify that the valves to the roughing pump, turbo pump, and hydrogen leak (located on the sides of the cabinet) are closed securely.

2. Open the air-purge valve (located on the side of the cabinet), and allow the system to reach ambient pressure.

3. Open the test chamber to the atmosphere by removing the Ultratorr fitting from the outer end of the test chamber. Check to see that two glass-encapsulated magnets (one for inserting and one for removing the sample after the test) are located in the ends of the test chamber.

4. Using the external magnet, and while wearing gloves to handle the inner magnet, remove the inner magnet from the tube.

5. While wearing gloves or using forceps, insert the characterized test sample into the unheated end of the test chamber. Insert the inner magnet back into the outer end of the tube and replace and tighten the Ultratorr fitting.

6. Begin pumping down the test chamber by slowly opening the valve to the roughing pump.

7. When the roughing pump has pumped down to $<0.1$ torr, close the roughing pump valve and slowly open the valve to the turbo pump. Allow the system to pump down for 10 to 15 minutes.

8. With the test-chamber pressure at zero, close the turbo pump valve to isolate the test chamber and begin timing the 10-minute leak check.

9. If the leak check is successful $\left(<1 \times 10^{-3}\right.$ torr $\left./ \mathrm{min}\right)$, open the hinged lid of the furnace. Without delay and using the external magnet, slide the test sample into the middle of the heated zone of the furnace (near the tip of the thermocouple) and reclose the lid of the furnace. 
10. Allow the furnace to return to the test temperature (usually $\sim 2$ minutes).

11. While the furnace chamber is reheating, slowly open the standard hydrogen leak to release hydrogen gas trapped between the valve and orifice.

12. As the system pressure increases, open the roughing pump valve and completely open the standard hydrogen leak. Evacuate the system with the rough pump until the system vacuum is $<0.1$ torr.

13. Close the roughing-pump valve and open the turbo-pump valve.

The system is now ready to begin a getter rate test. The next step is to start the computer and datalogger software to begin logging pressure/time data.

\subsection{Datalogger Operation}

The operation of the computer and data-logging software is described in detail in the separate "Personal Daq User's Manual" and is beyond the scope of this User's Guide. Refer to the Personal Daq User's Manual for instructions on the use of the A/D conversion module and the data-logging software.

The data-logger file that collects the pressure/time data throughout the test should be named with a unique name that simplifies identifying the file with a particular sample and test. In addition to the data logger results, an example data sheet is shown in Attachment A that identifies the sample, its dimensions, test conditions, readings, etc. that should be recorded over the course of the test, and become part of the test Records.

\subsection{Getter Rate Measurement}

The getter rate test can be conducted using either one of two methods, or both methods if desired. The basis for the two-part test is described in the section "Theory of Operation."

\subsubsection{Part 1-Pressure Plateau Method}

With the test system being pumped down with the turbo pump, the standard hydrogen leak flowing, the test sample in place in the heated zone of the furnace tube, and the data logger running, the "plateau" test is ready to start.

1. Begin by closing the turbo pump valve. The pressure in the system will start to rise.

2. Record the "start time" on the data sheet, test log, etc.

3. As the pressure rises, the rate of rise will decrease until the curve becomes horizontal. The system pressure should stabilize at this "plateau" pressure where the rate that hydrogen is being absorbed (gettered) by the test sample is just equal to the rate that hydrogen is flowing into the system through the standard hydrogen leak.

4. Once the test is established at the "plateau," close the shut-off valve on the standard hydrogen leak.

5. Record the "end time" on the data sheet. (When performing both Parts 1 and 2 of this test, the end time from Part 1 becomes the start time for Part 2.) 


\subsubsection{Part 2-Pressure Decay Method}

Starting from the "plateau" pressure (or other beginning pressure as may be specified by controlling documents, etc.), with the standard hydrogen-leak shut off, the roughing-pump and turbo-pump valves closed, the test sample in place in the heated zone of the furnace tube, and the data logger running, the "pressure decay" test is ready to begin.

1. Close the valve on the standard hydrogen leak. The system pressure will start decreasing.

2. As the test nears the end, the system pressure will decrease to a lower limit and eventually stabilize at the endpoint (refer to Figure 1.1). This lower pressure value will typically be very near to zero. Note the end pressure on the data sheet.

3. A final pressure value greater than zero usually means that some gas species is present that is not absorbed by the getter (something other than hydrogen). This may come from something offgassing from the getter, but most likely, it is water vapor formed from hydrogen gas reducing some oxide on the surface of the getter. This water vapor is not absorbed by the getter. Although, as the hydrogen is absorbed by the getter at the end of the test, the water vapor may slowly be "cracked" into hydrogen and oxygen, such as by the bare zirconium at the cut ends of a tube specimen. The liberated hydrogen can then be absorbed by the getter, resulting in a slowly decreasing final pressure rather than a horizontal line, as shown in Figure 5.1. A slowly increasing final pressure may indicate that a slow leak has developed in the system during the test or was not noticed at the beginning. Leaks less than the $1 \times 10^{-3} \mathrm{~atm} \mathrm{cc} / \mathrm{sec}$ criteria should not affect the calculation of the getter rate coefficient. Final pressures greater than $10 \%$ of the plateau or starting pressure will require adjustment of the starting pressure to compensate for the pressure contribution of the unabsorbed species (i.e., subtract the final pressure from the starting pressure in the calculation). This is described more in the following section "Excel Spreadsheet Calculations."

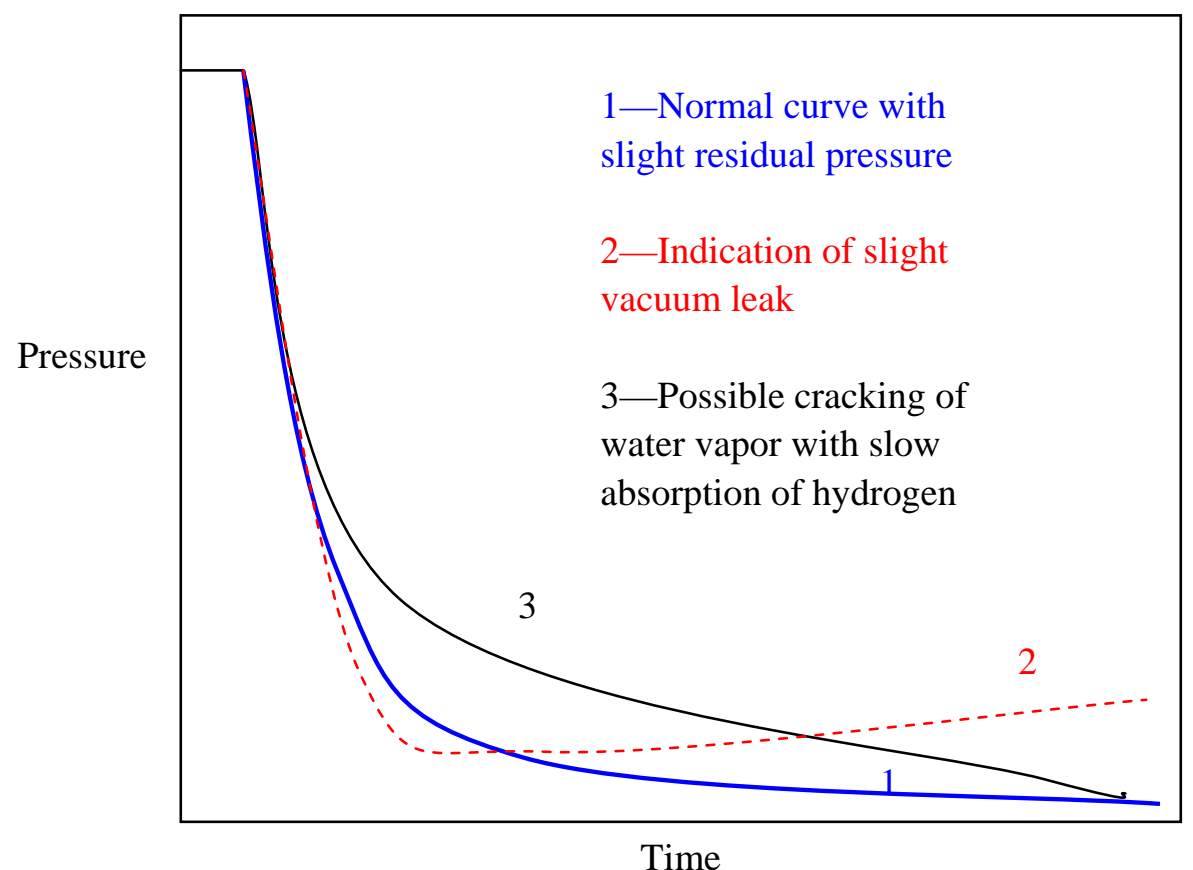

Figure 5.1. Possible Outcomes for Pressure Decay Test 
4. When the "final pressure" has been determined, the test is complete. Save the data file and shut off the data logger. Slide the test sample out of the heated zone of the furnace tube using the external and internal magnets and allow the sample to cool in the outer end of the test chamber.

5. Vent the test chamber to the atmosphere by opening the air-purge valve.

6. Open the Ultratorr fitting and remove the test sample.

\subsubsection{Excel Spreadsheet Calculations}

This section describes taking the pressure vs. time data from the data file, importing it into Excel, and performing the calculations necessary to determine the getter rate coefficient. Two Excel templates may be used (one for each test chamber, since they may have different volumes) with the necessary formulas embedded in the appropriate cells to perform the calculations. (Refer to the example Excel spreadsheet in Figure 5.2 for the following steps.)

1. Open the correct spreadsheet template file.

2. Enter the test number, date, sample number, etc.

3. Save the file under a new name that is identifiable to the test.

4. Enter the sample dimensions (length and diameter) from the data sheet.

5. Check that the value for the chamber volume $\left(\mathrm{m}^{3}\right)$ is correct.

6. Open the data-logger file, and import it into Excel.

7. Select the appropriate ranges of cells for time and pressure.

8. Copy the time and pressure columns from the data-logger spreadsheet to the appropriate location on the calculation worksheet.

9. Fill in the column under "elapsed time" (ET), starting with zero and in appropriate increments (e.g., $0,0.5,1.0 \ldots \mathrm{min}$ ).

10. Scan down the pressure column to locate the pressure (torr) that corresponds to the plateau pressure of the test. Highlight this cell for easier subsequent reference.

11. Copy the contents of the highlighted cell into the upper cell under the heading "Plateau Ps, (torr)".

12. The getter rate coefficient is automatically calculated in the cell to the right under the heading "Ka".

13. To calculate the rate coefficient for the 2 nd part of the test (declining pressure), select the first row of cells under the headings "ET, P, Ra, and Ka to the right of the time and pressure data. Then with the drag symbol (+) in the lower right of the selected range, pull down to the last row of the time/pressure data. This will fill the cells with elapsed time (sec), pressure (Pa), getter rate, and rate coefficient.

14. Scan down the rows to the previously highlighted cell with the plateau pressure. Below this is the beginning of the declining pressure part of the test. The rate coefficient near the beginning of the declining pressure section is compared to the plateau pressure rate coefficient. They should agree within $\pm 35 \%$ indicating an acceptable test. If the values do not agree, one must look for a reason such as an air leak, residual water vapor pressure, etc. as described above under Part 2 - Pressure Decay Method.

15. Copy the values of rate coefficient (plateau and decay) to the data sheet. Save the file, and exit Excel if done. Repeat the above steps for the data analysis for each test. 


\begin{tabular}{|c|c|c|c|c|c|c|c|}
\hline & \multicolumn{6}{|c|}{ Getter Rate Test Calculation Spreadsheet } & \\
\hline Test No: & Date: & Sample No & & & & & \\
\hline \multicolumn{8}{|l|}{$\begin{array}{l}\text { Additional } \\
\text { Description: }\end{array}$} \\
\hline Leak Rate & $\begin{array}{l}\text { Sample } \\
\text { Length }\end{array}$ & $\begin{array}{l}\text { Sample } \\
\text { Diameter }\end{array}$ & $\begin{array}{c}\text { Surface } \\
\text { Area }\end{array}$ & & Plateau Ps & $\begin{array}{l}\text { Part } 1 \\
\text { Getter Rate } \\
\text { Coefficient }\end{array}$ & $\begin{array}{l}\text { Test } \\
\text { Chamber } \\
\text { Volume }\end{array}$ \\
\hline (atm.cc/sec) & (in) & (in) & $\left(m^{2}\right)$ & & (torr) & $\mathrm{Ka}$ & $\left(\mathrm{m}^{3}\right)$ \\
\hline \multirow[t]{8}{*}{$Z \times 10^{-1}$} & $x . x x x$ & $x . x x x$ & XX.XXX & & $x . x x x$ & $N \times 10^{-x}$ & X.XXXX \\
\hline & & $\begin{array}{r}\text { Time } \\
\text { data }\end{array}$ & & $\begin{array}{r}\text { Pressure } \\
\text { data } \mathrm{f}\end{array}$ & $\begin{array}{l}\text { from } \\
\text { le }\end{array}$ & & \\
\hline & Time & $\begin{array}{l}\text { Elapsed } \\
\text { Time }\end{array}$ & Pressy re & Elapsed Time & Pressure & Getter Rate & $\begin{array}{c}\text { Part } 2 \\
\text { Getter Rate } \\
\text { Coefficient }\end{array}$ \\
\hline & $(\mathrm{hh}: \mathrm{m})$ & $(\min )$ & (tor $)$ & $(\mathrm{sec})$ & $(\mathrm{Pa})^{-}$ & $\mathrm{Ra}$ & $\mathrm{Ka}$ \\
\hline & $9: 30$ & 0 & $x$ & 0 & $\mathrm{y}$ & $\mathrm{zzz}$ & $N \times 10^{-x}$ \\
\hline & $9: 31$ & 1 & $x$ & $60^{\circ}$ & $y$ & $\mathrm{ZZZ}$ & $\mathrm{N} \times 10^{-\mathrm{x}^{-}}$ \\
\hline & $9: 32$ & 2 & $x$ & 120 & $y$ & $\mathrm{ZZZ}$ & $N \times 10^{-x^{-}}$ \\
\hline & $9: 33^{-1}$ & 3 & $x$ & 180 & $y$ & $\mathrm{zzz}$ & $N \times 10^{-x}$ \\
\hline
\end{tabular}

Figure 5.2. Example Spreadsheet Calculation for Getter Rate Coefficient 


\subsection{Maintenance/Calibration}

The following maintenance items should be checked at regular intervals to keep the equipment in proper condition:

\begin{tabular}{|l|c|}
\hline \multicolumn{1}{|c|}{ Description } & Suggested Interval \\
\hline \hline Roughing Pump Oil replacement & Annual \\
\hline Foreline Trap Molecular Sieve Alumina replacement & Biennial or As needed \\
\hline Roughing Pump rebuild (kit available from manufacturer) & As Needed \\
\hline Ultratorr Fitting O-Ring replacement & As Needed \\
\hline Vacuum Valve Seat replacement & As Needed \\
\hline
\end{tabular}

The following M\&TE items must be calibrated at the proper intervals in accordance with the governing Quality Assurance Plan:

\begin{tabular}{|c|c|}
\hline Description & Suggested Interval \\
\hline "Type K Thermocouples & Biennial \\
\hline MKS Pressure Transducers & Annual \\
\hline Standard Hydrogen Leaks & Annual \\
\hline Data Logger & Annual \\
\hline
\end{tabular}

